\title{
A Mini Review on Diagnosis of Johne's disease in Livestock
}

\author{
M. Geetha* and K.M. Palanivel \\ Department of Veterinary Preventive Medicine, Veterinary College and Research Institute, \\ Namakkal-2, Tamil Nadu, India \\ *Corresponding author
}

\begin{tabular}{|l|l|}
\hline \multicolumn{1}{l}{ A B S T R A C T } \\
$\begin{array}{l}\text { Keywords } \\
\text { avium, Bacilli, } \\
\text { Diagnosis. }\end{array}$ & $\begin{array}{l}\text { Paratuberculosis (Johne's disease) is a chronic disease affecting livestock } \\
\text { especially ruminants. The disease is caused by Mycobacterium avium } \\
\text { subspecies paratuberculosis (MAP) an acid fast bacilli. The disease is } \\
\text { characterized by emaciation, progressive weight loss and chronic enteritis } \\
\text { unresponsive to treatment. This paper describes a mini review on diagnosis } \\
\text { of Johne's disease. }\end{array}$ \\
\hline $\begin{array}{l}\text { Accepted: } \\
\text { 07 September 2017 } \\
\text { 10 Octoble Online: }\end{array}$ & \\
\hline \hline
\end{tabular}

\section{Definition}

Paratuberculosis (Johne's disease) is widely distributed throughout the world and is caused by Mycobacterium avium subspecies paratuberculosis (MAP) (Baumgartner and Johnannes, 2008). The disease mainly affects domestic and wild ruminants (Chiodini et al., 1984) but MAP can also be found in numerous monogastric animals (Klee, 2002). Johne's disease (JD) characterized by emaciation, progressive weight loss and chronic enteritis unresponsive to treatment (Moges et al., 2016).

\section{Agent}

Mycobacterium avium subspecies paratuberculosis (MAP) is a gram positive, slow growing acid fast bacillus (Ayele et al., 2001). Strains of this microbe are I (sheep),
II (Cattle) and III (intermittent) (Gwozdz, 2010). It has wide host range and able to survive outside the host for longtime (more than 9 months) and therefore it seems more insidious than any other bacteria to animal health (Begg and Whittington, 2010). Ovine and caprine paratuberculosis involves chronic inflammatory lesions of the intestinal and lymphoid organs caused mostly by one or other of the 'S'(Sheep), 'C'(Cattle) or 'Bison type' strains of MAP (Windsor, 2014). The MAP may survive high temperature short time pasteurization (Manning and Collins, 2001).

\section{Host}

Mycobacterium avium subspecies paratuberculosis (MAP) affects domesticated 
and wild ruminants including cattle, sheep, goats, ilamas, alpaca, camels, moose, elk, bighorn sheep, buffalo and deer (Moges et al., 2016). Cattle, buffaloes, sheep and goat are the most infected species of domestic animals with JD (Rosseels and Huygen, 2008). In wild animals almost all ruminants get infected with JD including giraffe, deer and wild goats (De lisle and Collins, 1995). Camels are also prone to JD infection (Al-Ghamdi, 2013). In addition, MAP has been isolated from many non-ruminant species including rabbits, cats, foxes, weasel, badgers, bears, raccoons, woodmice and Norway rats. It also has been found in jackdaw, rook and crows (Sweeney, 2011). Horses and dogs can be infected experimentally (Van Leeuwen et al., 2006).

\section{Transmission}

The MAP bacterium is excreted with faeces, the most important source of infection, but is as well shedded in milk and ejaculate (Chiodini et al., 1984). The transmission mainly takes place in calves via faecal-oral route by contamination of feed and udder, or by intake of infectious milk and colostrum. The MAP excreted in great numbers in the faeces and affected animals shed organisms in faeces and milk (Hines et al., 2007). Soil, feed (pasture and hay) and drinking water and anything that is placed in contact with infected excrements can become a secondary source of contamination (Whitlock et al., 2000). Contaminated food, water, vehicles and other equipment may be a source of infection and responsible factors for MAP transmission from one flock to another flock (Ayele et al., 2001). More recent studies have shown that transplacental infection occurs in sheep and goats (Lambeth et al., 2004).

\section{Clinical signs}

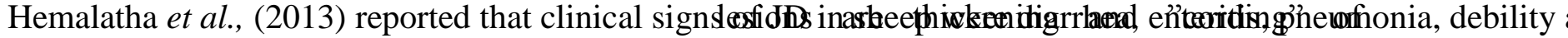
Stage III is clinical disease. Stage IV is lymphatic vessels on serosal surface and advanced clinical disease. For every clinical case, there may be 10-15 sub clinically infected sheep in the flock (Dieguez, 2008). This phenomenon is referred to as "Johne's iceberg". The number of observed cases is just the tip compared to the number of subclinical (or incubating) animals in the flock (Singh et al., 2007).

\section{Diagnosis}

A wide array of procedures and laboratory tests ranging from conventional methods like skin sensitivity test, Ziehl-Neelsen (ZN) staining and histopathological analysis of terminal ileum and mesenteric lymph nodes (Buergelt and Ginn, 2000) have been employed for its diagnosis. Diagnosis is based on clinical signs, postmortem lesions, and laboratory confirmation characteristics including direct test e.g. fecal smears, polymerase chain reaction (PCR) and indirect tests e.g., delayed-type hypersensitivity (DTH), interferon Assay, Enzyme linked immune-sorbent assay (ELISA), Agar gel immunodiffusion (AGID) and complement fixation test (CFT) (Munir et al., 2014).

\section{Clinical samples}

Clinical samples like faeces, milk and blood were collected aseptically in a sterile manner from an individually clinically suspected JD animal to diagnose the presence of paratuberculosis. Diagnosis best confirmed by the collection of multiple intestinal wall and mesenteric lymphnode in dead animals (OIE, 2004).

\section{Postmortem diagnosis}

The primary macroscopic lesions of JD in ruminants are usually confined to the ileum caecum, colon and draining lymphnodes. The 
along mesentry to enlarged lymphnodes, pale and oedematous, hypertrophy of lower small intestine, thick mucosal folds ("like convulsions of cerebral cortex") and folds erased by stretching (Sweeny, 2013).

\section{Laboratory Diagnosis}

\section{Ziehl-Neelsen (ZN) /acid fast staining of faecal smears}

Sohal et al., (2007) reported that staining of fecal samples for acid-fast bacilli (AFB) may reveal mycobacterial bacilli but the sensitivity of this method is low. Singh et al., (2011) found that screening of 153 fecal samples by ZN staining detected 15 (57.6\%) sheep and 17 $(68 \%)$ goats were positive for acid fast bacilli. Vinodhkumar and Gunaseelan (2012a) reported that the $\mathrm{ZN}$ staining can effectively used for surveillance of JD in clinically suspected animals and when animals were in diarrheic phase. Vinodhkumar and Gunaseelan (2012b) reported that 56 sheep were positive by absorbed $\mathrm{ZN}$ staining technique. Geetha et al., (2014) reported that sensitivity and specificity of Z-N staining technique in identification of MAP infection compared with PCR were 5.8 and 100 percent respectively.

\section{Culture}

Culture traditionally has been used as the definitive diagnostic for JD (Stevenson, 2008). It is used for fecal samples and tissues acquired postmortem but is unsuitable for milk or blood samples for which it has poor sensitivity and specificity (Irrenge et al., 2009). Most diagnostic laboratories employing culture as an automated liquid culture system such as BACTEC 460 radiometric system, BACTEC MGIT 960 fluorescence detection system or the TREK ESP pressure detection system (Stevenson, 2008). These systems have the advantage over solid medium culture in that they reduce the incubation required to detect growth from 12 20 weeks to 8-10 weeks for Type II (cattle type) strains. Cultures grown using these systems also have to be tested using a MAPspecific PCR to confirm that they are MAP (Whittington, 2009).

\section{Molecular diagnosis}

\section{Polymerase chain reaction $(\mathrm{PCR})$}

The insertion element IS 900 has been routinely used to detect the presence of MAP as it was shown to be present only in MAP (Collins et al., 1989). The PCR has been investigated as a diagnostic method for JD since the identification of the MAP-specific insertion sequence IS 900 (Green et al., 1989). The IS 900 has a unique nucleotide sequence which can be specifically detected by hybridization or PCR techniques. Sequences of IS 900 proved to be highly sensitive and specific markers of MAP among other slowly growing, acid fast bacteria, because IS 900 has been detected in field isolates of MAP from several hosts but never in other bacterial species. The MAP strains harbor multiple copies of IS900 at several sites of their chromosomes (Millar et al., 1995). He reported that when primer $\mathrm{p} 90$ and p91 for IS 900 were used for amplification of MAP DNA, they specifically recognize a 413 bp sequence of MAP. Vansick et al., (2004) used different sets of primer for efficient detection of paratuberculosis. Mobius et al., (2006) reported IS 900 remains a favourite target sequence for amplification of MAP specific loci.

\section{Detection of humoral immune response}

The commonly used immunological tests to detect humoral immune response to MAP infection are CFT, AGID and ELISA (Collins et al., 2006). 
Enzyme linked immunosorbent assay (ELISA)

Clarke (1996) reported that variable sensitivity of ELISA detection of in multibacillary and pauci-bacillary condition of JD. Perez et al., (1996) reported that vowing to high specificity of serological tests in sheep, they could be used for the screening and control of JD in sheep flocks. The ELISA like PCR had a lower sensitivity compared to tissue culture and was not over sensitive (Kumar, 2002).

Singh et al., (2007) reported that the test sensitivity varies and depends on the stages of disease represented within the herd or flock and the antigens used in the serologic test. The sensitivity of ELISA has been reported to be 87-100 percent for sheep showing clinical signs. The ELISA is considered as a standard procedure of detecting antibodies for MAP cases (Gupta et al., 2012). The sensitivity of ELISA in serum of animals is $7 \%$ in the silent stage, $15 \%$ in the subclinical stage and $85 \%$ to 98\% in the clinical stage (Gilardoni et al., 2012). The sensitivity of ELISA in MAP cases it increases with disease progression (Donat et al., 2014).

\section{Detection of cell-mediated immunity}

The cell-mediated immune (CMI) response is considered to be a key determinant of immunity to all mycobacterial infections with the humoral response giving little or no protection (Chiodini and Herman, 1996). He reported that the CMI response occurred early in infection and therefore tests to detect CMI had the potential to detect infected animals before shedding of MAP occurs.

\section{Delayed type hypersensitivity (DTH)}

Delayed type hypersensitivity is measured by injecting intradermal antigens (Johnin or
Avian Purified Protein Derivative) in skin to detect cell mediated immunity. Reaction is allowed to occur and after 72 hours and increased in skin thickness of more than 4 $\mathrm{mm}$ will give the indication of positive result (Manning and Collins, 2001).

\section{Gamma - interferon assay (IFN-Y)}

Buffy coat (leukocytes) is collected from heparinized blood and exposed to antigen to measure CMI by the release of gamma interferon (Manning and Collins, 2001). This method is successfully used for detection of cytokines for the indication of CMI to check exposure of animal to MAP (Nielsen and Toft, 2008). This test shows a low sensitivity when used to detect infection in a herd with mixed infection of tuberculosis and paratuberculosis (Alvarez et al., 2009). The advantage of the IFN-Y test is the significant secretion of IFN-Y occurs during the early stages and may be used to detect animals in the subclinical stage (Stabel and whittlock, 2001).

\section{References}

Al- Ghamdi, G.M., 2013. Mycobacterium avium subspecies paratuberculosis in camels, clinical aspects and control suggestions. Egypt. Acad. J. Biolog. Sci., 5 (1): 11-15.

Alvarez, J., L. De Juan, J. Bezos, B. Romero, J.L. Saez, O. Minguez, A. Mateos, L. Dominduez and A. Arnaz, 2009. Effect of paratuberculosis on the diagnosis of tuberculosis in a goat flock with a natural mixed infection. Vet. Microbiol, 128: 72-80.

Ayele, W.Y., M. Machackova and I. Pavlik, 2001. The transmission and impact of paratuberculosis infection in domestic and wild ruminants. Vet. Med. Czech., 46 (7-8): 205-224.

Baumgartner, W., and L.K. Johannes, 2008. 
Paratuberculosis - potentials and limits of control programs XXV. Jubilee World Buiatrics Congress 2008, 7-10.

Begg, D., and R. Whittington, 2010. Paratuberculosis in sheep. In: Behr, M., and D.M. Collins (Eds), paratuberculosis: organism, Disease, Control. CABI, 157- 164.

Buregelt, C.D., and P.E. Ginn, 2000. The histopathologic diagnosis of subclinical Johne's disease in North American Bison (Bison bison). Vet. Microbiol, 77(3-4): 325-331.

Chiodini R.J., H.J. Van Kruiningen and R.S. Merkal, $1984 . \quad$ Ruminant paratuberculosis (Johne's disease): The current status and future prospects. Cornell Vet., 74(3):218-62.

Chiodini, R.J., and T.J. Hermon, 1996. Paratuberculosis: A potential zoonosis. Vet. Clin. N. Am. (Food Anim. Pract), 12: 457-467.

Clarke, C.J., 1996. The pathology and pathogenesis of paratuberculosis in ruminants and other species. $J$. Comp.Pathol., 116: 217-261.

Collins, D.M., D.M. Glabric and G.W. Lisle, 1989. Identification of a repetitive DNA sequence specific to Mycobacterium paratuberculosis. FEMS Microbiolo. Lett, 60: 175-178.

Collins, M.T., G. Lisby, D. Chicks, S. Christensen, M. Reichrelderfer, N. Hoiby and V. Binder, 2006. Results of multiple diagnostic tests for Mycobacterium avium subsp. paratuberculosis in patients with inflammatory bowel disease and in controls. J.clin. Micobiolo., 38: 43734281.

De Lisle, G.W., and D.M. Collins, 1995. Johne's disease in deer. Vet Rec., 136336.

Dieguez, F.J., 2008. Management practices associated with Mycobacterium avium subspecies paratuberculosis infection and effects of the infection on dairy herds. Vet. Rec., 162: 614-617.

Donat, K., K. Schiotter, G. Erhardt and H.R. Brandt, 2014. Prevalence of paratuberculosis in cattle and control measures within the herd influence the performance of ELISA tests. Vet. Rec., 175(5): 119-121.

Geetha, M., K.M. Palanivel and G. Selvaraju, 2014. Assessing the infection status of Mycobacterium avium subspecies paratuberculosis in small ruminants. Indian Vet. J., 9 (12): 74-76.

Gilardoni, C., L. Saucier, and W.J. Meadus, 2012. Mycobacterium avium subp. paratuberculosis in dairy products, meat, drinking water. J. Food. prot., 74: 480-499.

Green, E.P., M.L.V. Tizard, M.T. Moss, J. Thompson, J.J. Mcfadden and J. Hermon-taylor, 1989. Sequence and characterization of IS 900, an insertion element identified in a human Crohn's disease isolate of Mycobacterium paratuberculosis. Nucleic Acids Res., 17: 9063-9073.

Gupta, A., S.M. Agarwal and P.K. Gupta, 2012. Sero-prevalence of paratuberculosis (Johne's disease) in cattle population of south western Bangalore using ELISA kit. Open. $J$. Vet. Med., 2: 196-200.

Gwozdz, J.M., 2010. Paratuberculosis (Johne's disease) Australian and New Zealand standard Diagnostic procedures, August 2010.

Hemalatha, S., Parimal Roy, V. Purushothaman and M. Iyue, 2013. Paratuberculosis in different breeds of sheep: A retrospective study of cases. Int. J. of Mycobacteriology, 2: 166-170.

Hines, M.E., J.R. Sweeney, F. Griffin, A.M. Talaat, D. Bakker, G. Benedictus, G. Davis, A. Koets, G. Pruitt and R.H. Whitlock, 2007. Experimental challenge models for Johne's disease: A review 
and proposed international guidelines. Vet. Microbiol, 122: 197-222.

Irrenge, L.M., K. Walravens, M. Govaerts, J.Godfroid, K. Huygen and J.L. Gala, 2009. Development and validation of a triplex real- time PCR for rapid detection and specific identification of Mycobacterium avium subspecies. paratuberculosis in faecal samples. Vet. Microbiol, 136: 166-172.

Klee, W., 2002. Paratuberkulose (Johne'sche Krankheit). In: Dirksen, G., H.D. Grunder, M. Stober, (Eds): Innere Medizin und Chirurgie des Rindes. Blackwell. Berlin. Pp.586-591.

Kumar, R., M.C. Prasad and O.P. Paliwal, 2002. Paratuberculosis in goats. A retrospective study. Indian Vet. J., 65: 582-584.

Lambeth, C., L.A. Reddacliff, P. Windsor, K.A. Abbott, H. McGregor and R.J. Whittington, 2004. Intrauterine and transmammary transmission of Mycobacterium avium subspecies paratuberculosis in sheep. Aust. Vet J., 82: 504-508.

Manning, J.B.E., and M.T. Collins, 2001. Mycobacterium avium subspecies paratuberculosis pathogen, pathogenesis and diagnosis. Rev. Sci. Tech. Off. Int. Epiz., 20(1): 133- 150

Millar, D., J. Ford, J. Sanderson, S. Withey, M. Tizard, T. Doran and J. Hermon Taylor, 1995. IS 900 PCR to detect Mycobacterium paratuberculosis in retail supplies of whole pasteurized cow milk in England and Wales? Appl. Environ. Microbiol, 62: 3446- 3452.

Moges, S., S. Mohammed, G. Gashaw, H. Belete, Z. Mebrae and K. Hayat 2016. Review on bovine paratuberculosis. World. J. of Pharma. Med. Res, 2(5): 17-24.

Munir, M., J.M. Garrido, G. Aduriz and M.V. Geijo, 2014. Detection of Mycobacterium avium subspecies paratuberculosis in ovine faeces by direct quantitative PCR has similar or greater sensitivity compared to radiometric culture. Vet. Microbiol, 125: $36-48$

Nielsen, S.S., and M. Toft, 2008. Assessment of management- related risk factors for paratuberculosis in Danish dairy herds using Bayesian mixture models. Prev. Vet. Med., 81(4): 306- 317.

Office International des Epizooties (OIE), 2004. Paratuberculosis (Johne's disease). http. WWW. Oie. Int/chapter $\mathrm{X}$ 4.T.

Perez, V.J., J. Tellechea, M. Copra, M. Gutierrez and J.F. Garcia martin, 1996. Relation between pathologic findings and cellular immune response in sheep with natuarally acquired paratuberculosis. Am. J. Vet. Res., 60: 123-127.

Rosseels, V., and K. Huygen, 2008. Vaccination against paratuberculosis. Expert rev of Vac., 7(6): 817- 832.

Singh, A.V., S.V. Singh, P.K. Singh, J.S. Sohal and M.K. Singh, 2011. High prevalence of Mycobacterium avium subspecies paratuberculosis ('Indian bison type') in animal attendants suffering from gasterointestinal complaints who work with goat herds endemic for Johne's disease in India. Intl. J. Infect. Dis., 15(10): 677-683.

Singh, S.V., A.V. Singh, J.S. Sohal and A.V. Singh, 2007. Evaluation of an indigenous ELISA for diagnosis of Johne's disease and its comparison with commercial kit. Indian, J. Microbiol., 47 (93): 251-258.

Sohal, J.S., S.V. Singh, S. Swati, A.V. Singh, P.K. Singh, K. Sandhu, K Narayanasamy and A. Maitra, 2007. Mycobacterium avium subspecies paratuberculosis diagnosis and strain typing present status and future developments. Indian J. Experimental. 
Biol., 45: 843-852.

Stabel, J.R., and R.H. Whittlock, 2001. On farm batch pasteurization destroys Mycobacterium paratuberculosis in waste milk. J. Dairy sci., 84: 24-527.

Stevenson, K., 2008. Diagnosis of Johne's disease: Current Limitations and Prospects. Cattle practice, 18(2): 126137.

Sweeney, R.W., 2011. Pathogenesis of paratuberculosis. Vet. Clin. And Food Anim pract, 27: 537- 546.

Sweeney, R.W., 2013. Paratuberculosis (Johne's disease) in cattle and other susceptible species. J. Vet. Intern. Med., 26: $1239-1250$.

Van Leeuwen, J.A., G.P. Keefe, R. Tremblay, C. Power and J.J Wichtel, 2006. Seroprevalence of infection with Mycobacterium avium subspecies paratuberculosis, bovine leukemia virus and bovine viral diarrhea virus in maritime Canada dairy cattle. Can. Vet. J., 42: 193-198

Vansnick, E., 2004. Johne's disease in zoo animals: Development of molecular tools for the detection and characterization of Mycobacterium avium subspecies paratuberculosis.
Doctorial thesis: Instituutvoor Tropische Geneeskunde Department Diergeneeskunde.

Vinodhkumar, O.R., and L. Gunaseelan, 2012a. Use of Ziehl- Neelsen staining as a preliminary diagnostic tool for bovine paratuberculosis surveillance. Indian Vet. J., 89 (11): 122- 124.

Vinodhkumar, O.R., and L. Gunaseelan, 2012b. seroprevalence of ovine paratuberculosis. Indian Vet. J., 89(11): 124-126.

Whitlock, R.H., S.J. Wells, R.W. Sweeney and J. Vantiem, 2000. ELISA and fecal culture for paratuberculosis (Johne's disease): Sensitivity and specificity of each method. Vet. Microbiol, 77: 387398.

Whittington, R.J., 2009. In-utero infection with Mycobacterium avium subsp. paratuberculosis: A critical review and meta-analysis. Vet. J., 179: 60-69.

Windsor, P.A., 2014. Managing control programs for ovine caseous lymphadenitis and paratuberculosis in Australia and the need for persistent Vaccination. Vet Med. Res. Rep., 5: 1121.

\section{How to cite this article:}

Geetha, M. and Palanivel, K.M. 2017. A Mini Review on Diagnosis of Johne's disease in Livestock. Int.J.Curr.Microbiol.App.Sci. 6(10): 500-506.

doi: https://doi.org/10.20546/ijcmas.2017.610.061 